\title{
Geographic and ethnic differences in childhood leukaemia and lymphoma survival: comparisons of Philippine residents, Asian Americans and Caucasians in the United States
}

\author{
MT Redaniel', A Laudico ${ }^{2,3,4}$, MR Mirasol-Lumague ${ }^{4}$, AP Alcasabas ${ }^{5,6}$, D Pulte ${ }^{1,7}$ and H Brenner, \\ 'Division of Clinical Epidemiology and Aging Research, German Cancer Research Center, Bergheimer Str 20, Heidelberg D-69/ 15, Germany; ${ }^{2}$ Manila \\ Cancer Registry, Philippine Cancer Society, 310 San Rafael St, San Miguel, Manila I005, Philippines; ${ }^{3}$ Department of Surgery, Philippine General Hospital, \\ University of the Philippines-Manila, Taft Avenue, Manila 1000, Philippines; ${ }^{4}$ Department of Health-Rizal Cancer Registry, Rizal Medical Center, Pasig \\ Boulevard, Pasig City 1600, Philippines; ${ }^{5}$ Department of Pediatrics, Philippine General Hospital, University of the Philippines-Manila, Taft Avenue, \\ Manila 1000, Philippines; ${ }^{6}$ Department of Paediatrics, University Children's Medical Institute, National University Hospital, 5 Lower Kent Ridge Road, \\ Singapore 119074, Singapore; ${ }^{7}$ Division of Hematology/Oncology, Department of Medicine, University of Medicine and Dentistry of New Jersey, Newark, \\ NJ 07101 , USA
}

BACKGROUND: Childhood cancer survival estimates from developing nations are rare.

METHODS: Using the US SEER and the Manila and Rizal Cancer Registry databases in the Philippines, 5-year survival for childhood leukaemia and lymphoma in 200 I-2005 among Asian Americans were compared with both Filipinos and Caucasians in the United States. Estimates for patients in the United States in earlier time periods were compared with that of Philippine residents to estimate delay in achievements of comparable levels of survival.

RESULTS: Childhood leukaemia and lymphoma relative survival was much lower in Filipinos living in the Philippines (32.9 and 47.7\%) than in Asian Americans (80.1 and 90.5\%) and Caucasians (81.9 and 87\%). Achievement of comparable survival rates of Philippine residents lagged behind by 20 to $>30$ years compared with patients in the United States.

CONCLUSIONS: The large differences in survival estimates of US populations and Philippine residents highlight the deficiencies of paediatric cancer care delivery in the Philippines. The long survival lag underlines the need for major improvements in access to diagnostic and treatment facilities.

British Journal of Cancer (2010) I 03, I49- 154. doi:10.1038/sj.bjc.6605703 www.bjcancer.com

Published online 18 May 2010

(c) 2010 Cancer Research UK

Keywords: childhood; leukaemia; lymphoma; survival

Childhood cancer survival rates vary in different countries and ethnicities (Stiller et al, 2000; Bhatia et al, 2002; Gatta et al, 2002, 2003; Kadan-Lottick et al, 2003; Aplenc et al, 2006; Brenner et al, 2007; Linabery and Ross, 2008). Nevertheless, international (Gatta et al, 2002, 2003; Brenner et al, 2007) and ethnic (Stiller et al, 2000; Bhatia et al, 2002; Kadan-Lottick et al, 2003; Aplenc et al, 2006; Linabery and Ross, 2008) comparisons are relatively few, particularly with low-income countries, mainly because of the absence of data.

Survival comparisons between countries and ethnic groups are important to assess the magnitude of survival discrepancies and to examine the possible sources of variability. By comparing survival estimates of developing countries with those from developed nations along time periods, delay in achieving comparable survival levels can be quantified.

In this study, we provide up-to-date estimates of childhood leukaemia and lymphoma survival for the Philippine resident population and Asian Americans, who have similar ethnicity, and

*Correspondence: Dr H Brenner; E-mail: h.brenner@dkfz-heidelberg.de Received 17 February 2010; revised 21 April 2010; accepted 26 April 2010; published online 18 May 2010
Asian Americans and Caucasians from the United States, who have the same health-care system. To quantify delay in survival and determine lag time, 5-year estimates for various time periods between 1976-1980 and 2001-2005 were computed for children in the United States, and compared with the 2001-2005 survival estimates for Philippine residents.

\section{MATERIALS AND METHODS}

US data were abstracted from the database of the Surveillance, Epidemiology and End Results (SEER) Program Limited-Use Data (1973-2005) (SEER, 2008), which routinely collects data on cancer patients from selected populations in the United States. For this analysis, the SEER 9 and 17 databases were used. From the SEER 17 database, patients $0-14$ years of age, of either Asian-American or Caucasian origin, diagnosed with leukaemia or lymphoma based on the International Classification of Childhood Cancer (ICCC) definition (Steliarova-Foucher et al, 2005) between 1 January 1996 and 31 December 2005 were included. Death certificate only (DCO), in situ and autopsy cases were excluded. A total of 625 Asian-American and 6834 Caucasian children were 
included, comprising of 496 (79\%) leukaemia and $129(21 \%)$ lymphoma cases from the former, and 5344 (78\%) leukaemia and $1490(22 \%)$ lymphoma cases, from the latter group. In this study, Filipino Americans were combined with other Asian-American groups, because of their small numbers. From the SEER 9 database, patients $0-14$ years of age, regardless of race, and diagnosed with ICCC classified leukaemia or lymphoma between 1 January 1976 and 31 December 2005 were included. DCO, in situ and autopsy cases were likewise excluded, leaving 6913 leukaemia and 2253 lymphoma cases for the analysis.

The databases used in the analyses of the Philippine resident population came from the Philippine Cancer Society-Manila Cancer Registry (PCS - MCR) and the Department of Health-Rizal Cancer Registry (DOH-RCR). These registries cover the National Capital Region (NCR), more commonly known as Metro Manila, which is the largest urban metropolis, and the political, social, educational and economic centre. This population is wealthier and has better access to health-care and cancer diagnostic and treatment facilities than the rest of the country (NSCB, 2006). The Philippine registries follow the cancer registration definitions and data collection guidelines set by the International Agency for Research on Cancer and the International Association of Cancer Registries. They are regarded as among the highquality cancer registries from developing countries and have been regularly included in Cancer Incidence in Five Continents (Muir et al, 1987; Parkin et al, 1992, 1997, 2002; Curado et al, 2007).

From a list of patients diagnosed between 1 January 1996 and 31 December 2005, subjects were selected using the same inclusion and exclusion criteria as for the SEER 17 database. Survival status was assessed from death certificate notifications mentioning cancer as the cause of death, which were collected from the Local Civil Registry Offices. For those not identified as dead, active follow-up by personal visits to the patients or their families in the last known place of residence was used to confirm vital status.

From the 1500 childhood leukaemia and lymphoma cases registered in the PCS-MCR and DOH-RCR databases, $4(<1 \%)$ were excluded because of invalid data, and $232(16 \%)$ because of missing follow-up information. A total of 1264 (84\%) patients were left in the analysis, for whom anonymised data sets were prepared. Of the cases, $86 \%$ (1081) had leukaemia while the remaining $14 \%$ (183) had lymphoma.

The project proposal was approved by the ethics review board of the National Institutes of Health of the University of the Philippines Manila. The information obtained strictly conformed to the code of conduct stipulated by the Guidelines on Confidentiality for Population-Based Cancer Registries (International Association of Cancer Registries \& International Agency for Research on Cancer, 2004).

\section{Data analysis}

In this study, period analysis of survival analysis was used (Brenner and Gefeller, 1996). With this approach, only the survival experience of patients for the 2001-2005 period was included. It has been shown that period analysis provides more up-to-date estimates of survival that closely predict survival later observed for patients diagnosed in the relevant period (Brenner et al, 2002; Brenner and Hakulinen, 2002a, b; Tälback et al, 2004; Ellison, 2006; Steliarova-Foucher et al, 2007). Analyses were carried out by types of leukaemia ((Ia) ALL, (Ib) acute myeloid (AML), and other types, including (Ic) chronic myeloproliferative diseases, (Id) myelodysplastic syndrome and other myeloproliferative diseases and (Ie) unspecified and other leukaemias) and lymphomas ((IIa) Hodgkins (HL), (IIb) non-Hodgkin (NHL), and other types, including (IIc) Burkitt, (IId) miscellaneous lymphoreticular neoplasms and (IIe) unspecified lymphomas) (Steliarova-Foucher et al, 2005), by sex and by age $(<1,1-4,5-9$ and 10-14).
Owing to small sample sizes for the other subtypes, only the survival estimates for ALL, AML and NHL were separately computed.

Estimates of relative survival (calculated as the ratio of observed and expected survival) were derived using the so-called Ederer II method (Ederer and Heise, 1959) and life tables for the year 2000. Owing to the absence of life tables for other races, the life table for whites from the US National Center for Health Statistics (Arias, 2002) was used for both SEER populations. The life table for the Philippine resident population was derived from the projected population estimate and the actual mortality data for this area, obtained from the Philippine National Statistics Office. To compare overall survival estimates between the different cancer populations, age was adjusted using the distribution of the Filipinos patients. The age groups used were $<1,1-4,5-9$ and $10-14$.

To test for differences in survival between the ethnic groups, a novel modelling approach for period analysis (Brenner and Hakulinen, 2006) was used. First, age-specific numbers of patients at risk and of deaths by year of follow-up were calculated separately for each population group. Then, Poisson regression models were fitted, in which the numbers of deaths were modelled as a function of the group (Philippine residents or Asian Americans or US Caucasians) and year of follow-up (1, 2, 3, 4,5 - entered as a categorical variable), using the logarithm of the person-years at risk as offset, and accounting for late entries and withdrawals as half persons, as described in detail elsewhere (Brenner and Hakulinen, 2006). In models for all types of leukaemia and lymphoma (both sexes and separately for men and women), and for ALL, AML and NHL, we also included age groups. This approach allowed testing for significance of differences in survival, after accounting for differences in distribution of subgroups, based on $P$-values for the population parameter estimate. A significance level of $=0.05$ (two-sided testing) was used.

Using the SEER 9 database, period survival estimates for the years 1976-1980, 1981-1985, 1986-1990, 1991-1995, 1996-2000 and 2001-2005 were derived for children in the United States, using the same algorithms used for the Philippine residents, Asian Americans and US Caucasians. These survival estimates were then compared with those for the Philippine population in 2001-2005, using only the data from the SEER 9 registries, as these have information dating back to the early 1970s. The other SEER registries were only included in the programme in the 1990s and 2001 (National Cancer Institute, September 2005).

\section{RESULTS}

In all three populations and in both sexes, a majority of leukaemia cases were diagnosed as ALL (Table 1), whereas NHL was the commonest lymphoma subtype. However, the proportion of leukaemia patients with ALL was lower, and of patients with undifferentiated leukaemias and AML was higher in the Philippine resident population than in the United States $(P<0.0001)$. Among lymphoma patients, the proportion of children with HL was lower, and the proportion of children with other types of lymphoma was larger in Philippine residents $(P<0.0001)$. More men were diagnosed than women in all groups for both types of malignancies. For leukaemias, the differences in age distribution between the three populations were not large (Table 2). For lymphomas, while most cases were older than 5 years in all groups, Philippine residents were relatively younger than the SEER populations, with a larger proportion $(29.5 \%)$ of cases aged 4 years and below.

Age-adjusted, and type-, age- and sex-specific estimates of 5-year absolute and relative survival for the 2001-2005 period are shown in Table 3. Much lower leukaemia relative survival was observed in Filipinos living in the Philippines (32.9\%) than in 
Table I Tumour characteristics of childhood leukaemia and lymphoma patients among the Philippine resident population and Asian Americans and Caucasians from US SEER, 1996-2005

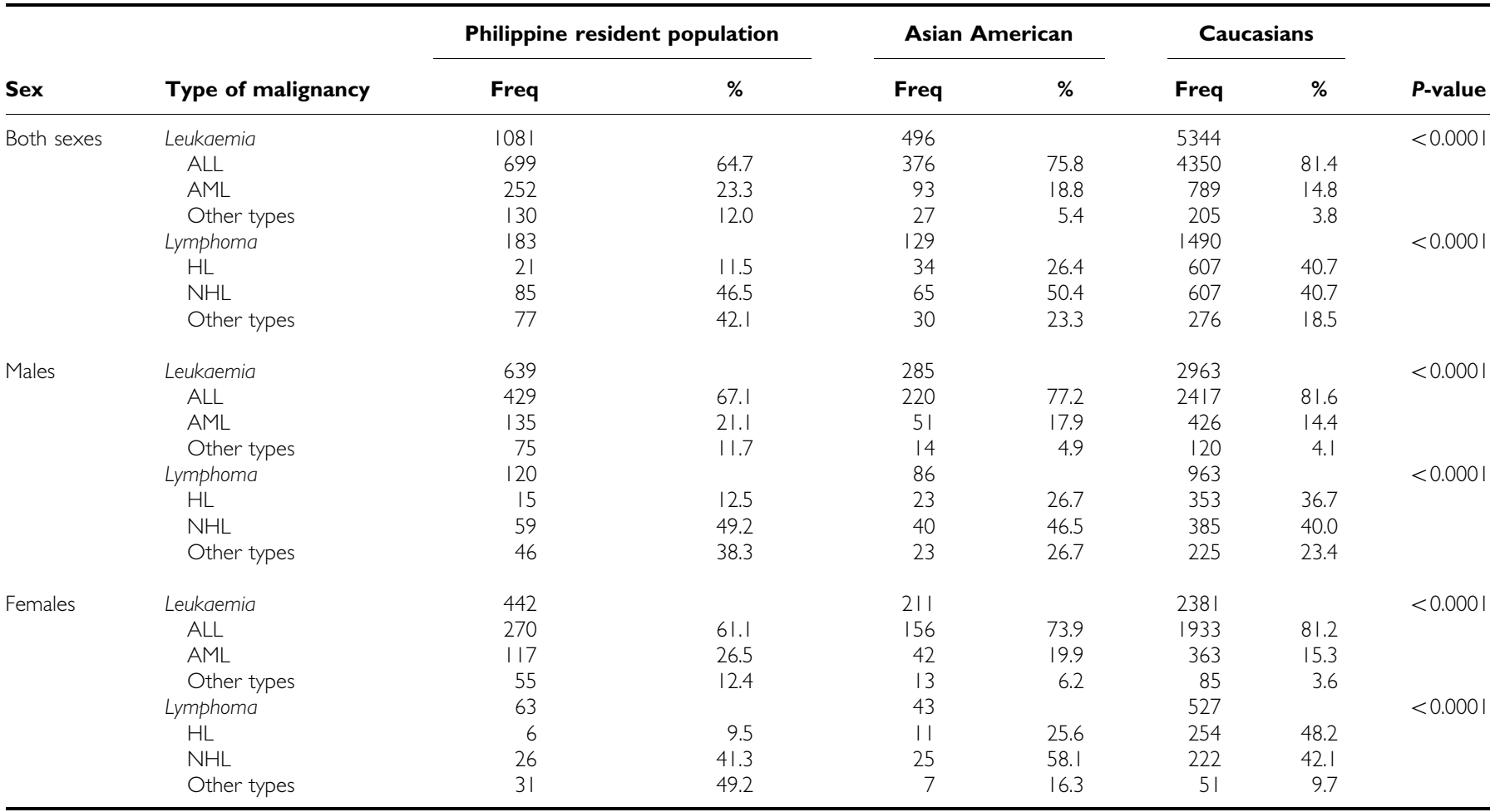

Abbreviations: $\mathrm{ALL}=$ acute lymphoblastic leukaemia; $\mathrm{AML}=$ acute myeloblastic leukaemia; $\mathrm{HL}=$ Hodgkin lymphoma; $\mathrm{NHL}=$ non-Hodgkin lymphoma; $\mathrm{SEER}=$ surveillance, epidemiology and end results.

Table 2 Childhood leukaemia and lymphoma patients among the Philippine resident population and Asian Americans and Caucasians from US SEER, 1996-2005, by age group

\begin{tabular}{|c|c|c|c|c|c|c|c|}
\hline \multirow[b]{2}{*}{ Age group } & \multicolumn{2}{|c|}{$\begin{array}{c}\text { Philippine } \\
\text { resident } \\
\text { population }\end{array}$} & \multicolumn{2}{|c|}{$\begin{array}{c}\text { Asian } \\
\text { American }\end{array}$} & \multicolumn{2}{|c|}{ Caucasians } & \multirow[b]{2}{*}{$P$-value } \\
\hline & Freq & $\%$ & Freq & $\%$ & Freq & $\%$ & \\
\hline Leukaemia & 1081 & & 496 & & 5344 & & 0.009 \\
\hline$<1$ & 67 & 6.2 & 34 & 6.9 & 319 & 6.0 & \\
\hline $1-4$ & 457 & 42.3 & 249 & 50.2 & 2527 & 47.3 & \\
\hline $5-9$ & 349 & 32.3 & 127 & 25.6 & 1455 & 27.2 & \\
\hline $10-14$ & 208 & 19.2 & 86 & 17.3 & 1043 & 19.5 & \\
\hline$A L L$ & 699 & & 376 & & 4350 & & $<0.001$ \\
\hline$<1$ & 38 & 5.4 & 18 & 4.8 & 142 & 3.3 & \\
\hline $\mid-4$ & 315 & 45.1 & 206 & 54.8 & 2211 & 50.8 & \\
\hline $5-9$ & 234 & 33.5 & 96 & 25.5 & 1241 & 28.5 & \\
\hline $10-14$ & 112 & 16.0 & 56 & 14.9 & 756 & 17.4 & \\
\hline Lymphoma & 183 & & 129 & & 1490 & & $<0.0001$ \\
\hline$<1$ & 2 & 1.1 & 2 & 1.6 & 10 & 0.7 & \\
\hline $1-4$ & 52 & 28.4 & 26 & 20.2 & 190 & 12.8 & \\
\hline $5-9$ & 52 & 28.4 & 32 & 24.8 & 449 & 30.1 & \\
\hline $10-14$ & 77 & 42.1 & 69 & 53.5 & 841 & 56.4 & \\
\hline
\end{tabular}

Abbrevaitions: ALL = acute lymphoblastic leukaemia; SEER = surveillance, epidemiology and end results.

Asian Americans (80.1\%) and Caucasians (81.9\%). Children with ALL have better survival than those with AML for all populations, but this advantage is small among Philippine residents. Survival estimates for men are slightly higher than for women in all three groups. Stratification by age reveals that the survival disadvantage of Philippine residents is particularly large for age group 10-14 years, where 5-year relative survival was as low as $17.6 \%$. For lymphoma, and NHL in particular, relative survival estimates for Philippine residents were likewise much lower (47.7 and $49.7 \%$, for lymphoma and NHL, respectively) than the US populations (90.5 and $84.8 \%$ for Asian Americans, and 87.0 and $81.0 \%$ for Caucasians).

Trends in 5-year survival for childhood leukaemia and lymphoma cases in the United States between 1976-1980 and 2001-2005 is shown in Table 4. For all groups, rates strongly increased over time, with improvements between the 1976-1980 and 2001-2005 periods ranging from 25 to $40 \%$. When compared with Philippine residents, survival estimates for patients from the Philippines in 2001-2005 were even lower than those for the US populations in 1976-1980, with the exception of AML, for which survival in the Philippines in 2001-2005 was similar to that for American children in 1981-1990.

\section{DISCUSSION}

In this comparative analysis of childhood leukaemia and lymphoma in 2001-2005, a strong survival disadvantage was observed for Philippine residents as compared with US children, while survival among Asian-American and Caucasian children was similar. Although estimates for Philippine children were expected to be lower than US patients, a lag in achievement of comparable survival rates of 20 to $>30$ years is disappointing. These survival rates highlight the deficiencies of paediatric cancer care in the Philippines, including unavailability of and inadequate access to diagnostic and treatment facilities, financial difficulties and lack of awareness. 
Table 3 Five-year survival (in \%) of childhood leukaemia and lymphoma patients, Philippine resident population and Asian Americans and Caucasians from US SEER, 200I-2005

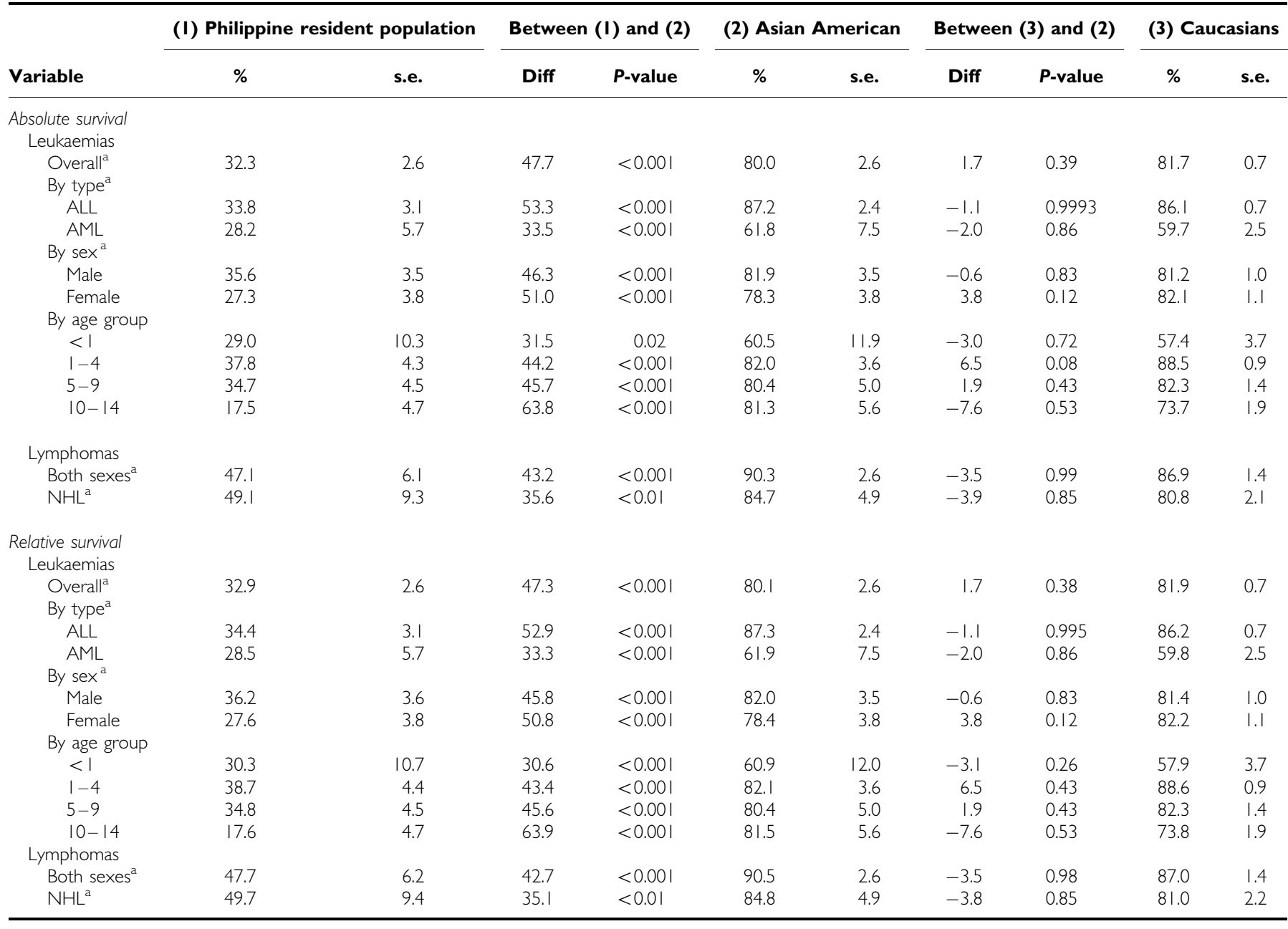

Abbreviations: $\mathrm{ALL}=$ acute lymphoblastic leukaemia; $\mathrm{AML}=$ acute myeloblastic leukaemia; $\mathrm{NHL}=$ non-Hodgkin lymphoma; $\mathrm{SEER}=$ surveillance, epidemiology and end results.

${ }^{a}$ Adjusted to the age distribution of the leukaemia/lymphoma of the patients from the Philippines.

In the Philippines, while state-of-the-art diagnostic and treatment modalities, such as immunophenotyping, cytogenetics, linear accelerator, MRI and PET-CT scan are present, these are inaccessible to most of the population. Services are available in paediatric oncology sections of large tertiary hospitals, which are few, mainly situated in major cities, and sometimes understaffed. Although there are adequate numbers of paediatric haematologists or oncologists in the country, there is no certified paediatric cancer unit (Ribeiro et al, 2008). A majority of the institutes and hospitals do not have full time paediatric haematologists-oncologists and specialised paediatric oncology nurses (Corrigan and Feig, 2004). Outside these units, diagnostic testing was described as nonexistent to limited, with a long wait for results at best, and availability of medications and blood products were limited or irregular, making supportive care for cancer patients poor (Ribeiro et al, 2008).

The expensive nature of paediatric cancer care further complicates the problem of inadequate health services and staff. The Philippines has a 2008 Gross National Income per capita of USD 3900 as compared with USD 46970 for the United States (World Bank, 2009). Although a national health-care insurance, PhilHealth, was introduced in 1997, its coverage is limited and most patients are not enrolled. Moreover, most patients cannot start treatment, and for those who do, treatment abandonment is common. In contrast, almost all children with cancer in the United States are treated in highly specialised paediatric oncology centres, which are a part of a national children oncology group. Furthermore, a special insurance programme covering children with serious illnesses, including cancer, is available (Centers for Medicare and Medicaid Services, 2009), resulting in a lower frequency of treatment discontinuation.

Lack of awareness is an important issue in the Philippines, especially on health problems relating to children, which leads to delays in seeking medical help and treatment (Usmani, 2001). Owing to the nonspecificity of signs and symptoms of early childhood leukaemia and lymphoma, most patients from developing countries are diagnosed at a later stage. For example, data from the Philippine General Hospital show that 55.3\% of newly diagnosed paediatric charity ALL cases diagnosed in 2003-2007 were high risk by US National Cancer Institute criteria, with more than half having an initial white blood cell count $>50000$ (Lubaton et al, 2009). Furthermore, $71 \%$ of newly diagnosed solid tumour patients in 2008 presented at stages III and IV. Similarly, inadequate education and poverty compel some parents to turn to traditional and alternative medicines for treatment (Usmani, 2001; Arora et al, 2007).

Similar survival estimates were observed between Asian Americans and Caucasians, consistent with previous findings (Kadan-Lottick et al, 2003). This could be attributed to the high 


\begin{tabular}{|c|c|c|c|c|c|c|c|c|c|c|c|c|}
\hline \multirow[b]{2}{*}{ Variable } & \multicolumn{2}{|c|}{$1976-1980$} & \multicolumn{2}{|c|}{$|98|-\mid 985$} & \multicolumn{2}{|c|}{$1986-1990$} & \multicolumn{2}{|c|}{$|99|-1995$} & \multicolumn{2}{|c|}{$1996-2000$} & \multicolumn{2}{|c|}{$200 I-2005$} \\
\hline & $\%$ & s.e. & $\%$ & s.e. & $\%$ & s.e. & $\%$ & s.e. & $\%$ & s.e. & $\%$ & s.e. \\
\hline \multicolumn{13}{|l|}{ Leukaemias } \\
\hline \multicolumn{13}{|l|}{ By type ${ }^{a}$} \\
\hline ÁLL & 60.7 & 3.1 & 67.4 & 1.7 & 74.2 & 1.5 & 79.1 & 1.4 & 85.6 & 1.1 & 88.1 & 1.0 \\
\hline Male & 49.4 & 3.9 & 58.1 & 2.2 & 64.1 & 1.9 & 71.0 & 1.8 & 77.9 & 1.6 & 82.6 & 1.4 \\
\hline Female & 56.1 & 3.7 & 62.2 & 2.2 & 69.3 & 2.1 & 73.8 & 1.9 & 81.1 & 1.7 & 83.5 & 1.6 \\
\hline \multicolumn{13}{|l|}{ By age group } \\
\hline$<1$ & 8.7 & 10.5 & 28.0 & 6.3 & 27.0 & 5.2 & 46.2 & 6.5 & 52.0 & 6.5 & 64.1 & 5.5 \\
\hline $1-4$ & 64.3 & 4.5 & 68.4 & 2.2 & 76.4 & 1.9 & 78.4 & 1.7 & 87.4 & 1.4 & 89.3 & 1.3 \\
\hline $5-9$ & 53.2 & 5.0 & 67.3 & 3.0 & 72.2 & 2.7 & 74.4 & 2.4 & 82.0 & 2.1 & 83.6 & 2.0 \\
\hline $10-14$ & 40.5 & 4.7 & 43.2 & 3.5 & 48.0 & 3.5 & 63.5 & 3.5 & 64.7 & 3.2 & 73.7 & 2.9 \\
\hline \multicolumn{13}{|l|}{ Relative survival } \\
\hline \multicolumn{13}{|l|}{ Leukaemias } \\
\hline Both sexes ${ }^{a}$ & 52.8 & 2.8 & 60.8 & 1.6 & 66.6 & 1.4 & 72.4 & 1.3 & 79.2 & 1.2 & 83.0 & I.1 \\
\hline ALL & 60.8 & 3.1 & 67.5 & 1.7 & 74.3 & 1.5 & 79.2 & 1.4 & 85.7 & 1.2 & 88.2 & 1.0 \\
\hline AML & 20.7 & 4.8 & 29.5 & 4.4 & 35.8 & 4.4 & 40.5 & 3.8 & 49.0 & 3.7 & 60.8 & 3.7 \\
\hline \multicolumn{13}{|l|}{ By $\operatorname{sex}^{a}$} \\
\hline Male & 49.5 & 3.9 & 58.2 & 2.2 & 64.2 & 1.2 & 71.1 & 1.8 & 78.1 & 1.6 & 82.7 & 1.4 \\
\hline Female & 56.2 & 3.7 & 62.3 & 2.2 & 69.4 & 2.1 & 73.9 & 1.9 & 81.2 & 1.7 & 83.6 & 1.6 \\
\hline \multicolumn{13}{|l|}{ By age group } \\
\hline$<1$ & 8.8 & 10.5 & 28.2 & 6.3 & 27.2 & 5.2 & 46.6 & 6.6 & 52.4 & 6.6 & 64.6 & 5.5 \\
\hline $1-4$ & 64.4 & 4.5 & 68.5 & 2.2 & 76.5 & 1.9 & 78.5 & 1.7 & 87.6 & 1.4 & 89.4 & 1.3 \\
\hline $5-9$ & 53.3 & 5.0 & 67.4 & 3.0 & 72.3 & 2.7 & 74.5 & 2.4 & 82.1 & 2.1 & 83.6 & 2.0 \\
\hline $10-14$ & 40.6 & 4.7 & 43.2 & 3.5 & 48.1 & 3.5 & 63.6 & 3.5 & 64.8 & 3.2 & 73.9 & 2.9 \\
\hline
\end{tabular}

Abbreviations: $\mathrm{ALL}=$ acute lymphoblastic leukaemia; $\mathrm{AML}=$ acute myeloblastic leukaemia; $\mathrm{NHL}=$ non-Hodgkin lymphoma; SEER $=$ surveillance, epidemiology and end results.

${ }^{a}$ Adjusted to the age distribution of the leukemia/lymphoma of the patients from the Philippines.

level of health-care access among Asian Americans, the majority of whom being either native born $(31 \%)$ or naturalised citizens (34\%) (Reeves and Bennett, 2004). Moreover, Asian Americans have higher earnings than the average American, with a large proportion having attained a bachelor's degree or more (44\%), and more likely to be in management, professional or related occupations (45\%) (Reeves and Bennett, 2004).

Taken together, our results underline the overwhelming importance of access to effective treatment as accounting for the observed survival differences between the populations studied. Even though some ethnic variability has been observed, under trial conditions with identical treatment and access (Aplenc et al, 2006), this variation was small compared with the huge variation according to the health-care system in our study.

Some limitations of our study are relevant because not all factors that could affect survival could be considered. Information not obtainable include factors related to cancer services, such as training and skills of health-care professionals, accuracy of diagnostic tests, chemotherapy protocols used, and disease characteristics such as cancer stage, and comorbidities. Furthermore, in spite of exhaustive measures to locate Philippine resident for survival information, including personal visits to the homes, follow-up was in complete for $25 \%$ of patients, attributable to the high migration and mobility in the study area. Nevertheless, it can be assumed that patients lost to follow-up have not received or have discontinued treatment, as follow-up information was not found or incomplete in hospitals within the NCR. The availability of cancer treatment is limited in the surrounding regions and it is unlikely that patients lost to follow-up have higher survival than those who were not.

In spite of these limitations, our results highlight the very large survival disadvantage of children in the Philippines. Efforts such as more twinning programmes between hospitals and specialised centres in developed and developing countries should be considered, as well as increased government spending on health, which have been shown to be effective in enhancing care of childhood leukaemia in developing countries (Pui and Ribeiro, 2003; Howard et al, 2004).

\section{ACKNOWLEDGEMENTS}

We thank the staff of the Manila and Rizal Cancer Registries (Siony Alcos, Zoila Bautista, Simplicio Franco, Andrei Luis Navarro, Lydia Navarro, Glenda Palomares, Ellen Santos, Minda Turano, Melinda Visoria, Arlene Sasot, Abigail Bagtas, Myralen Caraan, Kenshky Dimaapi, Wilma Grafilo, Portia de Guzman, Josephine Isla, Elena Marquez and Tess Medes) who facilitated data abstraction and encoding, and patient follow-up. Special mention also goes to the Philippine Cancer Society and the Rizal Medical Center. The work of Maria Theresa Redaniel was supported by a scholarship from the German Academic Exchange Service (DAAD). 


\section{REFERENCES}

Aplenc R, Alonzo TA, Gerbing RB, Smith FO, Meshinchi S, Ross JA, Perentesis J, Woods WG, Lange BJ, Davies SM (2006) Ethnicity and survival in childhood acute myeloid leukemia: a report from the Children's Oncology Group. Blood 108: 74-80

Arias E (2002) United States Abridged Life Tables, 2000. National Vital Statistics Reports; Vol. 51 no. 3 National Center for Health Statistics: Hyattsville, MD

Arora RS, Eden T, Pizer B (2007) The problem of treatment abandonment in children from developing countries with cancer. Pediatr Blood Cancer 49: $941-946$

Bhatia S, Sather HN, Heerema NA, Trigg ME, Gaynon PS, Robison LL (2002) Racial and ethnic differences in survival of children with acute lymphoblastic leukemia. Blood 100: 1957-1964

Brenner H, Coehbergh J, Parkin D, Izarzugaza I, Clavel J, Arndt V, Steliarova-Foucher E (2007) Up-to-date monitoring of childhood cancer long-term survival in Europe: leukemias and lymphomas. Ann Oncol 18: $1569-1577$

Brenner H, Gefeller O (1996) An alternative approach to monitoring cancer survival. Cancer 78: $2004-2010$

Brenner H, Hakulinen T (2002a) Advanced detection of time trends in long-term cancer patient survival: experience from 50 years of cancer registration in Finland. Am J Epidemiol 156: 566-577

Brenner H, Hakulinen T (2002b) Up-to-date long-term survival curves of patients with cancer by period analysis. J Clin Oncol 20: 826-832

Brenner H, Hakulinen $\mathrm{T}$ (2006) Up-to-date and precise estimates of cancer patient survival: model-based period analysis. Am J Epidemiol 164: $689-696$

Brenner H, Soderman B, Hakulinen T (2002) Use of period analysis for providing more up-to-date estimates of long-term survival rates: empirical evaluation among 370000 cancer patients in Finland. Int $J$ Epidemiol 31: 456-462

Centers for Medicare and Medicaid Services (2009) Children's Health Insurance Program. Department of Health and Human Services: Baltimore, MD

Corrigan JJ, Feig SA (2004) Guidelines for pediatric cancer centers. Pediatrics 113: $1833-1835$

Curado M, Edwards B, Shin H, Storm H, Ferlay J, Heanue M, Boyle P (eds) (2007) Cancer Incidence in Five Continents Vol. IX. IARC Scientific Publications No. 160 IARC: Lyon

Ederer F, Heise H (1959) Instructions to IBM 650 Programmers in Processing Survival Computations. National Cancer Institute: Bethesda, MD

Ellison L (2006) An empirical evaluation of period survival analysis using data from the Canadian Cancer Registry. Ann Epidemiol 16: $191-196$

Gatta G, Capocaccia R, Coleman M, Gloeckler Ries L, Berrino F (2002) Childhood cancer survival in Europe and the United States. Cancer 95: $1767-1772$

Gatta G, Corazziari I, Magnani C, Peris-Bonet R, Roazzi P, Stiller C, the EUROCARE Working Group (2003) Childhood cancer survival in Europe. Ann Oncol 14: v119-v127

Howard SC, Pedrosa M, Lins M, Pedrosa A, Pui CH, Ribeiro RC, Pedrosa F (2004) Establishment of a pediatric oncology program and outcomes of childhood acute lymphoblastic leukemia in a resource-poor area. JAMA 291: $2471-2475$

International Association of Cancer Registries, International Agency for Research on Cancer (2004) Guidelines on Confidentiality for PopulationBased Cancer Registries, Internal Report No. 2004/03. IARC: Lyon
Kadan-Lottick NS, Ness KK, Bhatia S, Gurney JG (2003) Survival variability by race and ethnicity in childhood acute lymphoblastic leukemia. JAMA 290: 2008-2014

Linabery AM, Ross JA (2008) Childhood and adolescent cancer survival in the US by race and ethnicity for the diagnostic period 1975-1999. Cancer 113: $2575-2596$

Lubaton C, Gonzales-Santos J, Alcasabas A (2009) Outcome of children with acute lymphoblastic leukemia at the charity service of the Philippine General Hospital, Manila, Philippines. In 3rd St Jude-Viva Forum in Pediatric Oncology: Hematologic Malignancies in Children, Singapore

Muir C, Waterhouse J, Powell J, Mack T, Whelan S (eds) (1987) Cancer Incidence in Five Continents Vol. V International Agency for Research on Cancer: Lyon

National Cancer Institute (2005) SEER-Surveillance, Epidemiology and End Results, NIH Publication No. 05-4772 National Cancer Institute: Bethesda, MD, USA

NSCB (2006) Metro Manila - A Gateway to the Philippines, 2005 edn National Statistical Coordinating Board: Makati

Parkin D, Muir C, Whelan S, Gao Y, Ferlay J, Powell J (eds) (1992) Cancer Incidence in Five Continents Vol. VI International Agency for Research on Cancer: Lyon

Parkin D, Whelan S, Ferlay J, Raymond L, Young J (eds) (1997) Cancer Incidence in Five Continents Vol. VII International Agency for Research on Cancer: Lyon

Parkin D, Whelan S, Ferlay J, Teppo L, Thomas D (eds) (2002) Cancer Incidence in Five Continents Vol. VIII International Agency for Research on Cancer: Lyon

Pui CH, Ribeiro RC (2003) International collaboration on childhood leukaemia. Int J Hematol 78: $383-389$

Reeves T, Bennett C (2004) We the People: Asians in the United States. Census 2000 Special Reports, CENSR-17. US Census Bureau: Washington, $\mathrm{DC}$

Ribeiro RC, Steliarova-Foucher E, Magrath I, Lemerle J, Eden T, Forget C, Mortara I, Tabah-Fisch I, Divino JJ, Miklavec T, Howard SC, Cavalli F (2008) Baseline status of paediatric oncology care in ten low-income or mid-income countries receiving My Child Matters support: a descriptive study. Lancet Oncol 9: 721-729

Steliarova-Foucher E, Arndt V, Parkin D, Berrino F, Brenner H (2007) Timely disclosure of progress in childhood cancer survival by 'period' analysis in the Automated Childhood Cancer Information System. Ann Oncol 18: $1554-1560$

Steliarova-Foucher E, Stiller C, Lacour B, Kaatsch P (2005) International classification of childhood cancer, third edition. Cancer 103: 1457-1467

Stiller CA, Bunch KJ, Lewis IJ (2000) Ethnic group and survival from childhood cancer: report from the UK Children's Cancer Study Group. Br J Cancer 82: 1339-1343

Surveillance Epidemiology and End Results (SEER) Program Limited-Use Data (1973-2005) National Cancer Institute, DCCPS, Surveillance Research Program, Cancer Statistics Branch, released April 2008, based on the November 2007 submission

Tälback M, Stenbeck M, Rosen M (2004) Up-to-date long-term survival of cancer patients: an evaluation of period analysis on Swedish Cancer Registry data. Eur J Cancer 40: $1361-1372$

Usmani GN (2001) Pediatric oncology in the third world. Curr Opin Pediatr 13: $1-9$

World Bank (2009) Gross National Income Per Capita 2008, Atlas Method and PPP. The World Bank: Washington, DC 